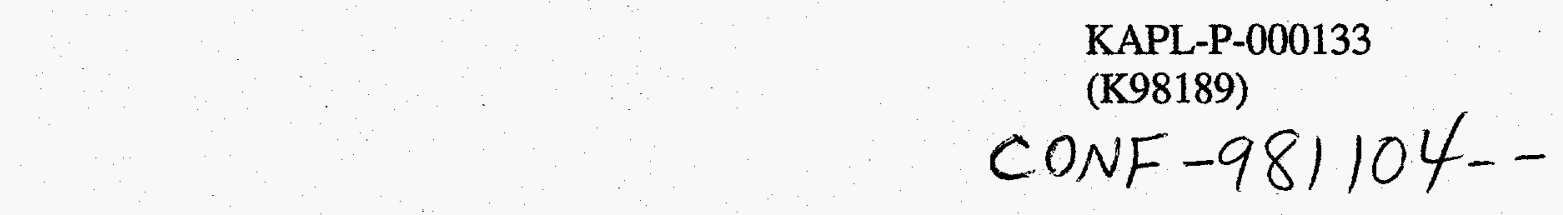

\title{
LIMITING PHASE SEPARATION IN EPITAXIAL GaInASSb
}

C. A. Wang, G. W. Charache

November 1998

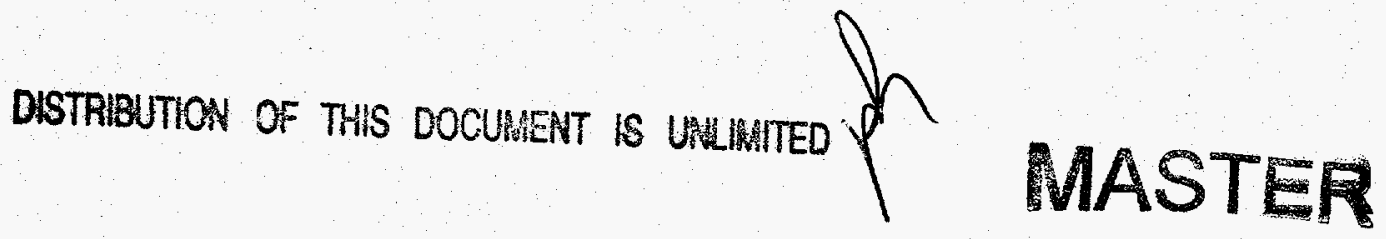

\section{NOTICE}

This report was prepared as an account of work sponsored by the United States Government. Neither the United States, nor the United States Department of Energy, nor any of their employees, nor any of their contractors, subcontractors, or their employees, makes any warranty, express or implied, or assumes any legal liability or responsibility for the accuracy, completeness or usefulness of any information, apparatus, product or process disclosed, or represents that its use would not infringe privately owned rights. 


\section{DISCLAIMER}

This report was prepared as an account of work sponsored by an agency of the United States Government. Neither the United States Government nor any agency thereof, nor any of their employees, makes any warranty, express or implied, or assumes any legal liability or responsibility for the acouracy, completeness, or usefulness of any information, apparatus, product, or process disclosed, of represents that its use would not iniringe privately owned rights. Refereace berein to any specific commercial product, process, or service by trade name, trademark, manufacturer, or otherwise does not necessarily constitute or imply its endorsement, recommendation, or favoring by the United States Government or any agency thereof. The views and opinions of authors expressed herein do not necessarily state or reflect those of the United States Governmeat or any agency thereof. 


\section{DISCLAIMER}

Portions of this document may be illegible in electronic image products. Images are produced from the best available original document. 
MRS 1998 Fall Meeting

Symposium H: Infrared Semiconductor Materials and Devices

\section{LIMITING PHASE SEPARATION IN EPITAXIAL GaInAsSb*}

C.A. Wang, S.L. Ransom, D.C. Oakley, H.K. Choi

Lincoln Laboratory, Massachusetts Institute of Technology, Lexington, MA 02420-9108

G.W. Charache, Lockheed Martin Corporation, Schenectady, NY 12301

Introduction - GaInAsSb alloys are of great interest for lattice-matched thermophotovoltaic (TPV) devices because of the high performance attainable at $2.2 \mu \mathrm{m}$. Extension of the TPV device cutoff wavelength to beyond $2.2 \mu \mathrm{m}$ is especially desirable since the emissive power of the source is significant at these longer wavelengths. However, the GaInAsSb quaternary alloy system exhibits a miscibility gap in the wavelength range of interest, and no devices with cutoff wavelengths longer than $2.3 \mu \mathrm{m}$ have been demonstrated. This paper reports the successful growth of GaInAsSb alloys which exhibit room temperature photoluminescence (PL) at wavelengths as long as 2.5 $\mu \mathrm{m}$. TPV devices with cutoff wavelengths out to $2.5 \mu \mathrm{m}$ exhibit external quantum efficiencies of $57 \%$. These values are comparable to those measured for $2.2 \mu \mathrm{m}$ devices.

Viewgraph 1 - This viewgraph shows the miscibility gap for $\mathrm{Ga}_{1-x} \mathrm{In}_{x} \mathrm{As}_{\mathrm{y}} \mathrm{Sb}_{1-\mathrm{y}}$ alloys. The solid curve shows the boundary between stable and metastable alloys at a temperature of $600^{\circ} \mathrm{C}$. Alloys inside the boundary are metastable. The dashed curves show the energy gap of the GaInAsSb alloys. The solid line corresponds to alloys that are lattice matched to GaSb substrates. GaInAsSb alloys that are lattice matched to Gasb and have energy gaps greater than $0.6 \mathrm{eV}(\sim 2.1 \mu \mathrm{m})$ are stable, while those less than $0.6 \mathrm{eV}$ (the alloys of interest for TPV's) are metastable according to the thermodynamic calculations. The composition of the metastable alloys lattice matched to GaSb have $\mathrm{x}$ and $y$ - values approximately greater than 0.1 . We have grown high quality GaInAsSb alloys into this miscibility gap with energy gap down to $0.5 \mathrm{eV}$.

Viewgraph $2-\mathrm{Ga}_{1-x} \operatorname{In}_{\mathrm{x}} \mathrm{As} \mathrm{sb}_{\mathrm{1-y}}$ epilayers were grown by organometallic vapor phase epitaxy (OMVPE) in a vertical rotating-disk reactor with $\mathrm{H}_{2}$ carrier gas at a flow rate of 10 slpm, reactor pressure of 150 Torr, and a typical rotation rate of $100 \mathrm{rpm}$. Solution *This work was sponsored by the Department of Energy under AF Contract No. F1962895-C-0002. The opinions, interpretations, conclusions and recommendations are those of the author and are not necessarily endorsed by the United States Air Force. 
trimethylindium (TMIn), triethylgallium (TEGa), tertiarybutylarsine (TBAs), and trimethylantimony (TMSb) were used as organometallic precursors. For doping studies, diethyltellurium (DETe) (10 ppm in $\mathrm{H}_{2}$ ) and dimethylzinc (DMZn) (1000 ppm in $\left.\mathrm{H}_{2}\right)$ were used as n- and p-type doping sources, respectively. Epilayers were grown at 525, 550 , and $575^{\circ} \mathrm{C}$. The growth rate was -2.5 to $5 \mu \mathrm{m} / \mathrm{h}$. Ga $a_{1-x} \mathrm{In}_{\mathrm{x}} \mathrm{As} \mathrm{s}_{\mathrm{y}} \mathrm{Sb}_{1-\mathrm{y}}$ epilayers were grown without a GaSb buffer on (100) Te-doped GaSb substrates misoriented $2^{\circ}$ toward (110) or $6^{\circ}$ toward (111)B. For electrical characterization, semi-insulating (SI) GaAs substrates of similar orientations were used because SI GaSb substrates are not available. The surface morphology was examined using Nomarski contrast microscopy and atomic force microscopy (AFM). High-resolution axis $x$-ray diffraction (HRXRD) was used to measure the degree of lattice mismatch to GaSb substrates. PL was measured at 4 and 300 $\mathrm{K}$ using a $\mathrm{PbS}$ detector. The microstructure was studied using transmission electron microscopy (TEM). Carrier concentration and mobility of GaInAsSb epilayers were obtained from Hall measurements based on the van der Pauw method, while secondary ion mass spectroscopy (SIMS) was used to determine the atomic concentration of dopants.

Viewgraph 3 - The distribution (incorporation) coefficient of In in GaInAsSb is shown here for epilayers grown at 525,550 , or $575^{\circ} \mathrm{C}$. Indium is more effectively incorporated at lower growth temperatures. At $525^{\circ} \mathrm{C}$, the In distribution coefficient is 1.2 , and decreases to 0.95 and 0.5 at 550 and $575^{\circ} \mathrm{C}$, respectively. The highest indium content in the GaInAsSb is $\sim 0.2$.

Yiewgraph 4 - The data for As incorporation indicate that the distribution coefficient is approximately unity independent of growth temperature. These results suggest that the TBAs and TMSb are completely pyrolized.

Viewgraph 5 - The degree of lattice mismatch of GaInAsSb epilayers on GaSb can influence the performance of the TPV devices. Therefore, we determined the sensitivity of lattice mismatch on the fraction of TBAs in the gas phase. The results show here that excellent control of lattice matching can be obtained with TBAs. The change in $x$-ray splitting is about 160 to 180 arc $\mathrm{sec}$ per $\mathrm{sccm} \mathrm{H}_{2}$ flow through the TBAs source.

Viewgraph 6 -Nomarski micrographs of the surface morphology of $\mathrm{Ga}_{1-\mathrm{x}} \operatorname{In}_{\mathrm{X}} \mathrm{Ass}_{\mathrm{S}} \mathrm{Sb}_{1-\mathrm{y}}$ layers lattice matched to GaSb substrates are shown here. The layers were grown at 525 
${ }^{\circ} \mathrm{C}$. The In and As concentrations were varied with $0.09<x<0.23$ and $0.08<y<0.21$. As the In and As concentrations increase, the surface morphology exhibits an increased 'wavy' texture. Layers with $x$ and $y$ values less than approximately 0.21 had a mirror-like appearance to the eye. For $x-0.23, y-0.21$, the surface was hazy.

Viewgraph 7 - AFM images corresponding to the layers shown in the previous viewgraph are shown here. A marked increase in surface roughness is measured as the $x$ - and $y$ values increase. The root-mean-square roughness for these layers is $0.2,0.8,1.5$, and 8 $\mathrm{nm}$, respectively, for layers with increasing $x$-and $y$-values. The surface features are oriented in the [011] direction for layers with $x, y<0.2$, and suggest a step-bunching growth mode. The irregular pattern observed for the layer with $x \sim 0.23, y \sim 0.21$ suggests a three-dimensional growth mode. The degradation in surface morphology may be related to the increased instability of the alloy since this composition corresponds to a region further inside the miscibility gap.

Viewgraph 8 - This viewgraph shows HRXRD $\omega \cdot 2 \Theta$ scans plotted on a log scale for GaInAsSb epilayers about $2 \mu \mathrm{m}$ in thickness. All layers are nominally lattice matched to the GaSb substrate. A dependence of the full width at half-maximum (FWHM) of the epilayer peak on the In and As concentrations is observed. For the epilayer with the lowest $x$ and $y$ values $(x=0.09, y=0.08)$, FWHM of the epilayer peak is comparable to that of the GaSb substrate ( 23 arc s). The FWHM increases to 32 arc $s$ with increasing Inand As-values. For $x=0.20, y=0.18$, the epilayer is matched to the substrate, but the scan is substantially broadened. This broadening may be related to a range of d-spacings associated with early stages of phase separation of the Ga1-x $\operatorname{In}_{X} \mathrm{As}_{\mathrm{y}} \mathrm{Sb}_{1-\mathrm{y}}$ metastable alloy to GaAs- and InSb- rich regions.

Viewgraph 9 - The PL from epilayers shown in the previous viewgraph is shown here. The peak emission for the sample with $x=0.09, y=0.08$ is 1818 and $2035 \mathrm{~nm}$ at 4 and $300 \mathrm{~K}$, respectively. The $4 \mathrm{~K}$ FWHM is $5.3 \mathrm{meV}$. With increasing $x$ and $y$ values, the 4 and $300 \mathrm{~K}$ emission increases to 2080 and $2320 \mathrm{~nm}$, respectively, for $\mathrm{x}=0.16, y=0.15$; and to 2225 and $2505 \mathrm{~nm}$, respectively. for $x=0.2, y=0.18$. The $4 \mathrm{~K}$ FWHM also increases to 7.5 and $25 \mathrm{meV}$, respectively. The longest PL emission at $300 \mathrm{~K}$ observed in our current study is $2525 \mathrm{~nm}$. 
Viewgraph 10 - This viewgraph summarizes the 4 K PL FWHM data for Ga1xInxAsySb1-y epilayers. These layers were grown at 525,550 , and $575^{\circ} \mathrm{C}$. Several trends are observed. The PL FWHM values are strongly dependent on growth temperature and peak energy. The lowest PL FWHM values are obtained for layers grown at the lowest temperature of $525^{\circ} \mathrm{C}$. The narrowest PL FWHM values are $-5 \mathrm{meV}$ for $4 \mathrm{~K}$ peak energy greater than $0.62 \mathrm{eV}$, and increase shaply below $0.60 \mathrm{eV}$. On the other hand, the PL FWHM increases below -0.63 and $0.67 \mathrm{eV}$ for layers grown at 550 and $575^{\circ} \mathrm{C}$, respectively. Since broadening in PL spectra can be a result of alloy scattering, the data are consistent with increased alloy clustering especially for layers with composition approaching the miscibility gap. These results suggest that under nonequilibrium conditions for OMVPE growth, the kinetics can have a significant influence on the extent of penetration into the miscibility gap. The smallest FWHM value measured is $4.7 \mathrm{meV}$ at $0.643 \mathrm{eV}$, which is the lowest value that has been reported for this alloy system grown by OMVPE.

Viewgraph 11 - This viewgraph shows plan view TEM micrographs for GaInAsSb with alloy composition in the stable region $(x=0.06 . y=0.05)$ and in the metastable region ( $x$ $=0.18, y=0.14$ ). The layer grown in the stable region is characterized by a uniform contrast, while that in the metastable region exhibits significant contrast. This contrast may arise from the compositional variations in the layer.

Viewgraph 12 - The composition was estimated from energy dispersive $x$-ray analysis, and the results are shown in this viewgraph. The lighter regions are InSb-rich compared to the bulk composition, while the darker regions are GaAs-rich. The compositional changes relative to the average concentrations are less than a few percent for the InSbrich regions and about 10 percent for the GaAs-rich regions.

Viewgraph 13 - The $300 \mathrm{~K}$ electrical properties of p-doped $\mathrm{Ga}_{1-\mathrm{x}} \mathrm{In}_{\mathrm{x}} \mathrm{Asy} \mathrm{Sb}_{1-\mathrm{y}}$ are summarized in this viewgraph. The $300 \mathrm{~K}$ PL wavelength of the layers represented by the closed circles is approximately $2.25 \mu \mathrm{m}$. The electrical properties of the p-type GaInAsSb depend on the epilayer composition. For $\mathrm{Zn}$-doped epilayers with $\mathrm{p} \sim 1 \times 10^{17} \mathrm{~cm}^{-3}$, the hole mobility decreases from 440 to $240 \mathrm{~cm}^{2} / \mathrm{V}-\mathrm{s}$ for 2.05 - and $2.5-\mu \mathrm{m}$ material. On the other hand, the electrical characteristics are similar for undoped GaInAsSb epilayers ( $p$ - 
type at $-1 \times 10^{16} \mathrm{~cm}^{-3}$ ). The $\mathrm{Zn}$ concentration as measured by SIMS is about 1.5 to 2 times higher than the measured hole concentration.

Viewgraph 14 - The $300 \mathrm{~K}$ electrical properties of n-doped GaInAsSb epilayers is shown here. The electron concentration ranges from $2.3 \times 10^{17}$ to $2.3 \times 10^{18} \mathrm{~cm}^{-3}$, with corresponding mobility values between 5208 and $2084 \mathrm{~cm}^{2} / \mathrm{V}-\mathrm{s}$, respectively. The electrical characteristics of the n-type layers are not dependent on the composition of the alloy. It should be noted, however, that Hall measurements could not be made on n-type GaInAsSb with $300 \mathrm{~K}$ PL wavelength $\sim 2.5 \mu \mathrm{m}$. The Te concentration measured by SIMS is about 1.5 to 2 times higher than the electron concentration.

Viewgraph 15 - This viewgraph shows the layer structure of the TPV devices, which were grown at $525^{\circ} \mathrm{C}$ on $(100) 6^{\circ}$ toward (111)B GaSb substrates. The structure consists of $0.1-\mu \mathrm{m}$-thick $\mathrm{n}$-GaSb buffer layer, 1- $\mu \mathrm{m}$-thick $\mathrm{n}$-GaInAsSb base layer (doped to $\sim 5 \times$ $10^{17} \mathrm{~cm}^{-3}$ ), 3- $\mu 11$-thick p-GaInAsSb emitter layer (doped to $2 \times 10^{17} \mathrm{~cm}^{-3}$ ), and 0.05 Hm-thick p-GaSb contact layor (doped to $-2 \times 10^{18} \mathrm{~cm}^{-3}$ ). The GaInAsSb alloy composition was varied to evaluate device performance as a function of cutoff wavelength.

Viewgraph 16 . The external quantum efficiency (QE) for several devices is plotted as a function of wavelength in this viewgraph. The external QE at $2 \mu \mathrm{m}$ is 56,54 , and $57 \%$, respectively for devices with cutoff wavelength of $2.3,2.4$, and $2.5 \mu \mathrm{m}$. At $2.5 \mu \mathrm{m}$, the $\mathrm{QE}$ is as high as $41 \%$ for the $2.5-\mu \mathrm{m}$ device. These high values of $\mathrm{QE}$ suggest that this characteristic of the TPV devices is not highly dependent on the specific characterization of materials properties reported in this study. 


\section{$\mathrm{Ga}_{1-\mathrm{x}} \mathrm{In}_{\mathrm{x}} \mathrm{As}_{\mathrm{y}} \mathrm{Sb}_{1-\mathrm{y}}$ Solid Immiscibility}

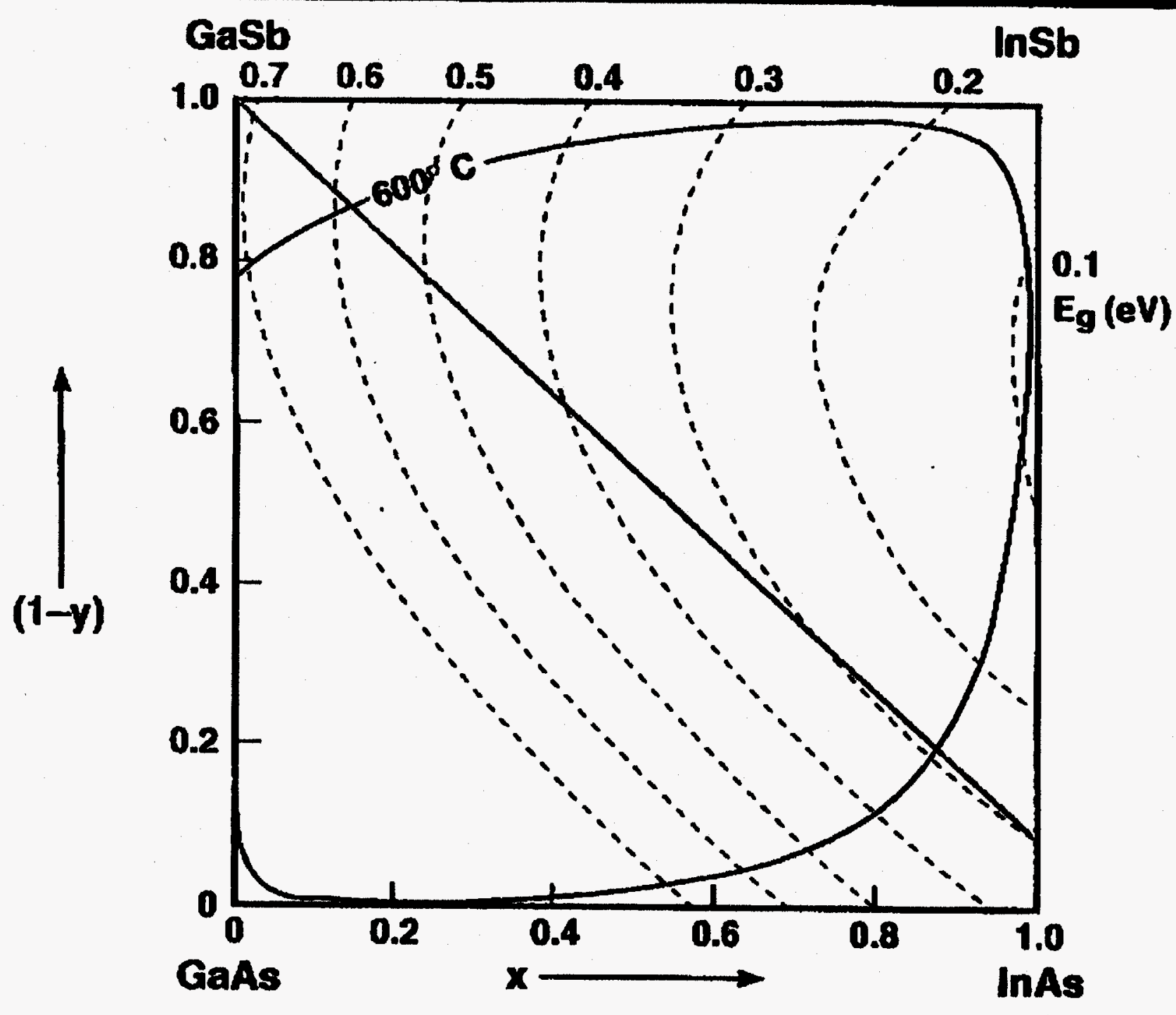

M. J. Cherng, ef al; J. Cryst. Growth 77, 408 (1986) 


\section{GalnAsSb Growth And Characterization}

- Sources:

- Triethylgallium (TEGa)

- Trimethylindium (TMIn, solution)

- Tertiarybutylarsine (TBAs)

- Trimethylantimony (TMSb)

- Dimethylzinc (DMZn, 1000 ppm in $\mathrm{H}_{2}$ )

- Diethyltellurium (DETe, $10 \mathrm{ppm}$ in $\mathrm{H}_{2}$ )

- Growth temperature: $525,550,575^{\circ} \mathrm{C}$

- V/ll ratio: 0.9 to 1.7

- Growth rate: 2.5 to $5 \mu \mathrm{m} / \mathrm{h}$

- Substrates: GaSb and SI GaAs

$-(100) 2^{\circ} \rightarrow(110)$

$-(100) 6^{\circ} \rightarrow(111) B$

- Vertical rotating-disk reactor operated at 150 TORR

- Characterization

- Nomarski contrast microscopy, XD, PL, TEM, Hall, SIMS viewgraph 2 


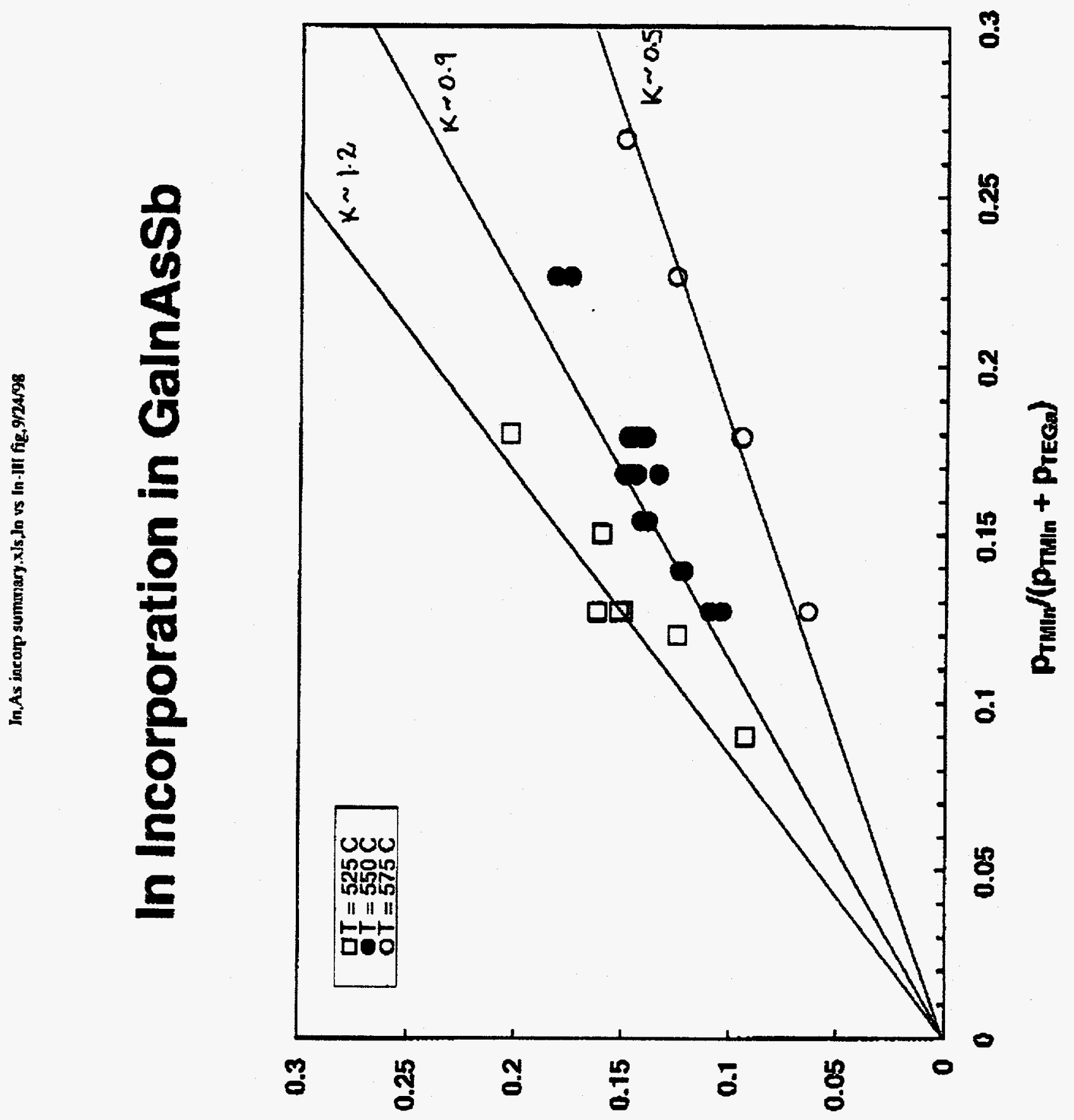

qssษujeg u! uा 


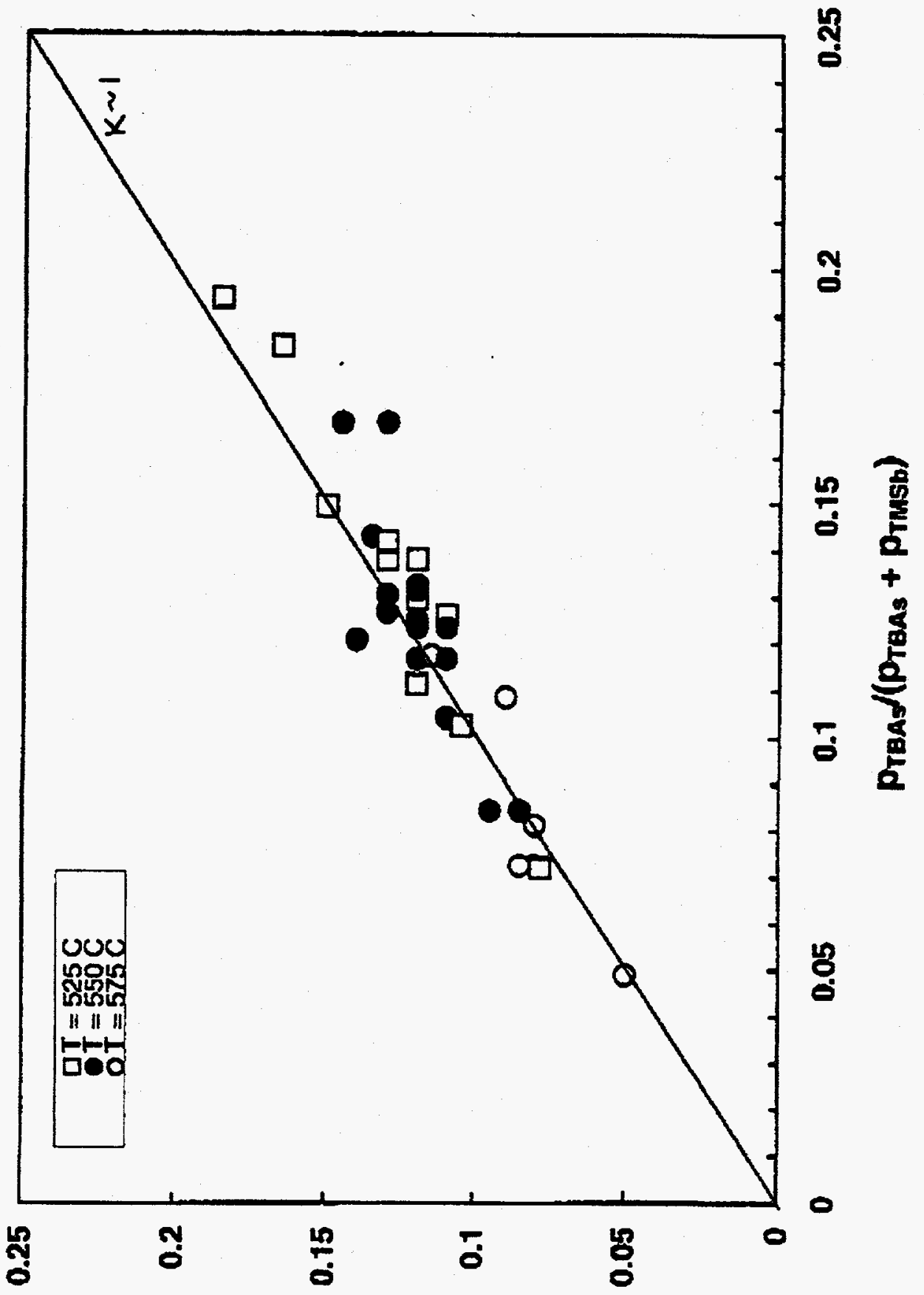

q5s*ules u! sy 


\section{Lattice Matching $\mathrm{Ga}_{1-\mathrm{x}} / \mathrm{n}_{\mathrm{x}} \mathrm{As} \mathrm{s}_{\mathrm{y}} \mathrm{Sb}_{1-\mathrm{y}} / \mathrm{GaSb}$ with Tertiarybutylarsine}

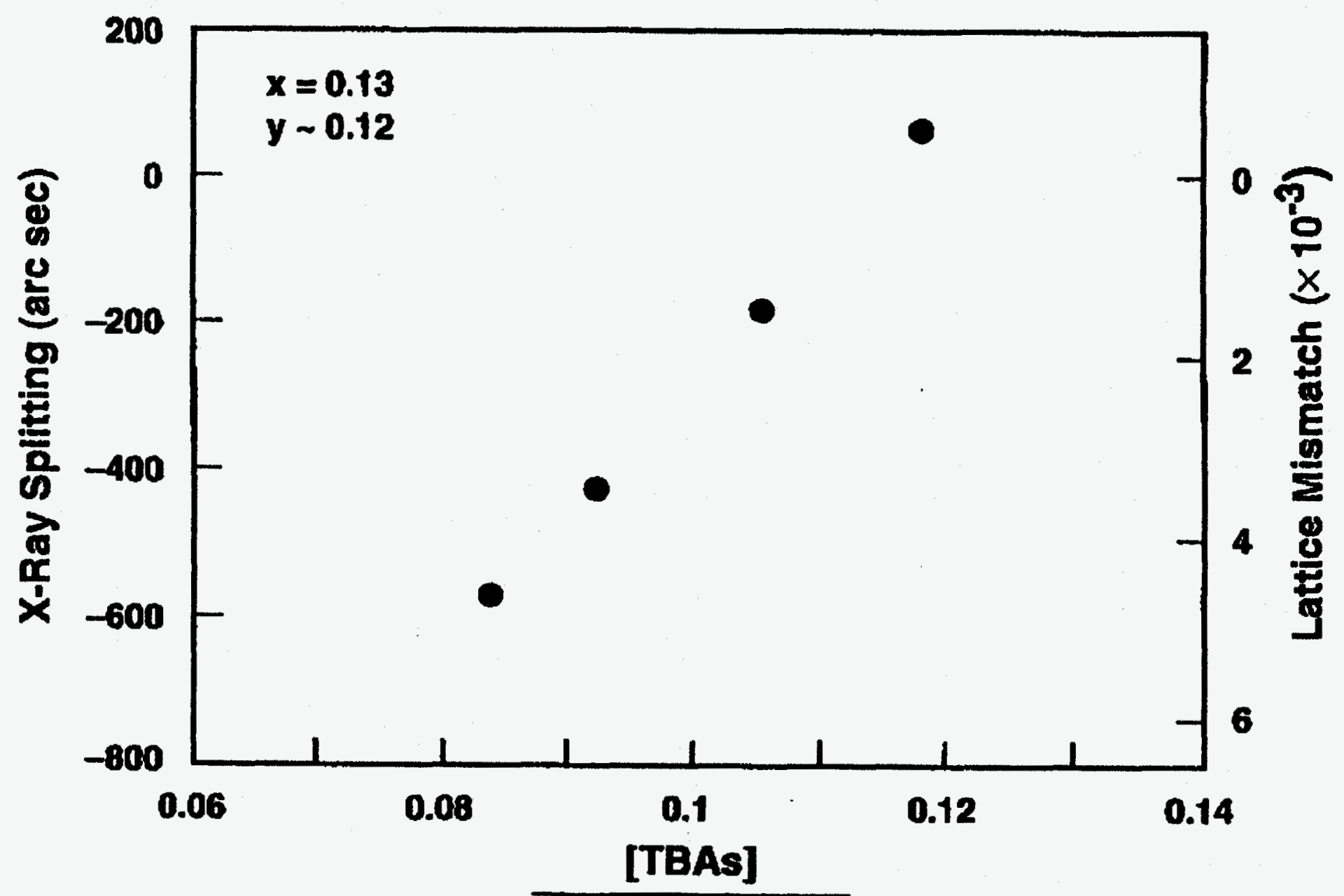

[TBAs] + [TMSb]

VLewgraph 5 


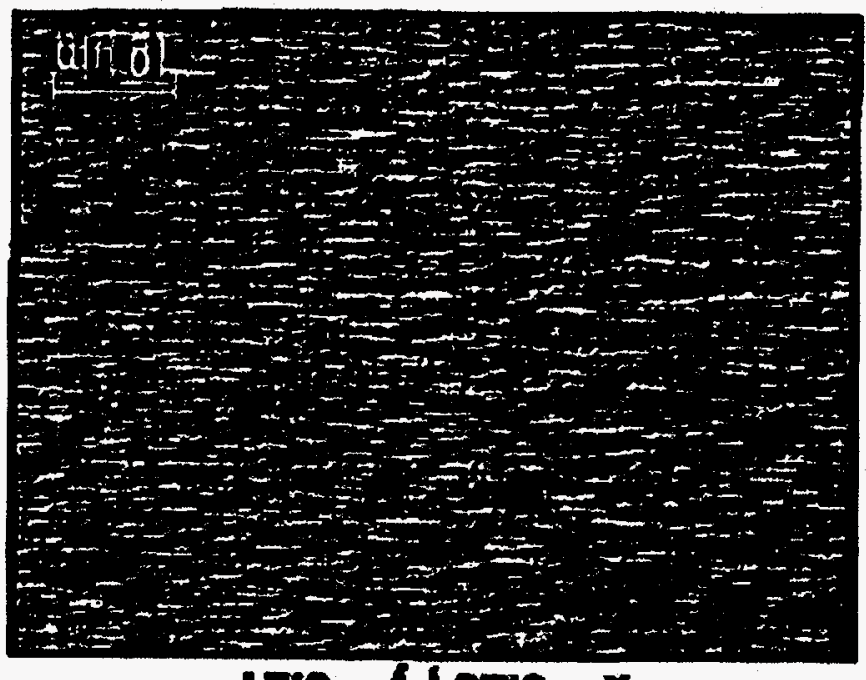

$\theta(L L) \leftarrow .9(00 L) \cdot 0.52 S=1$

$$
120-\Lambda^{1} 860 \sim x
$$

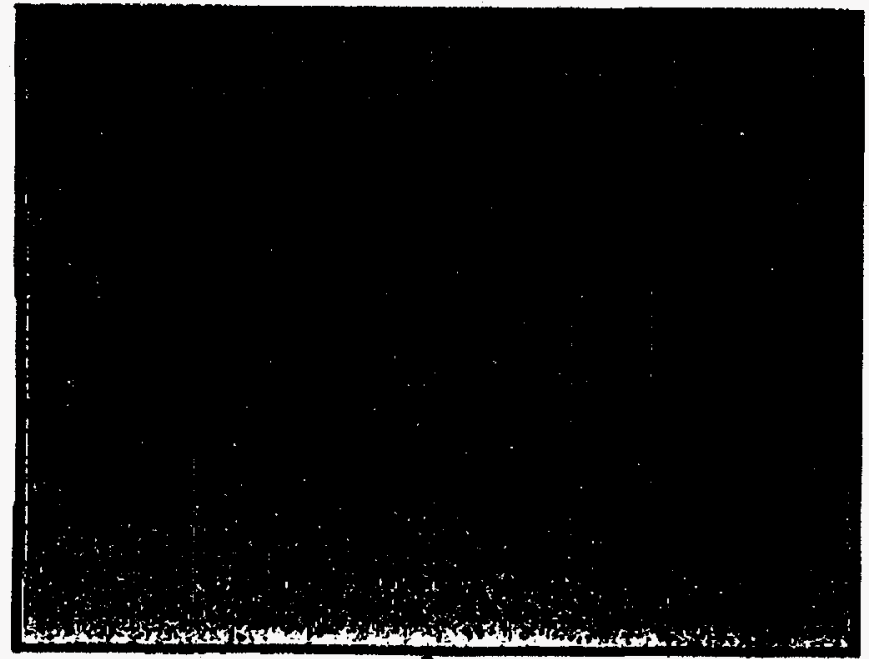

$910=A^{\prime} 91^{\circ} 0=x$
$810=A^{\prime} 020=x$ $80^{\circ} 0=\pi^{\top} 60^{\circ} 0=x$

\section{uolnsoduros to 10943

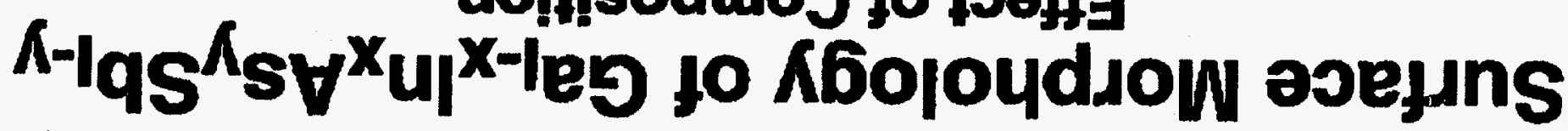




\section{X-Ray Diffraction of $G a_{1-x} / n_{x} A s_{y} S b_{1-y}$}
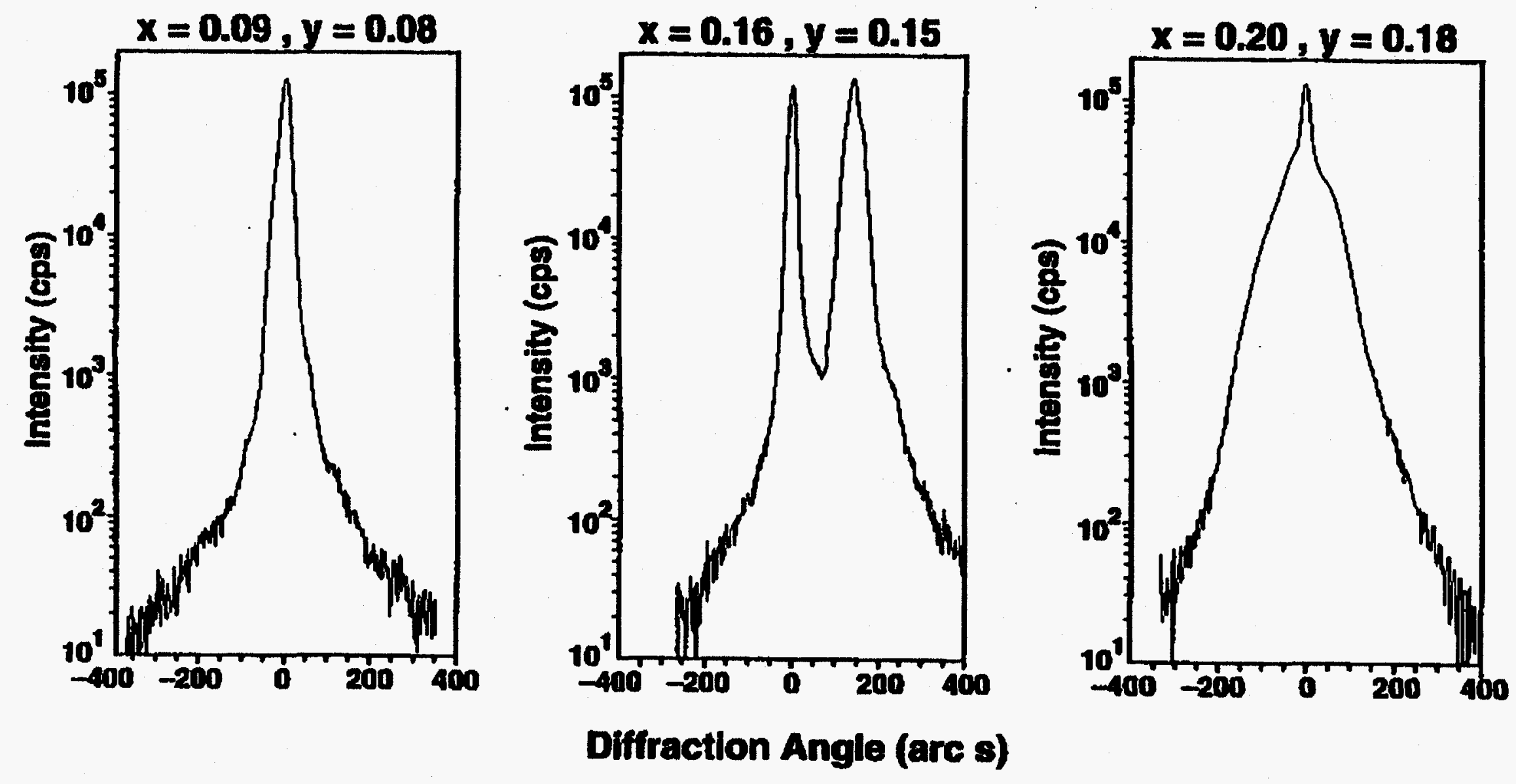

V1eurgraph 8 


\section{FWHM of 4K PL of GalnAsSb}

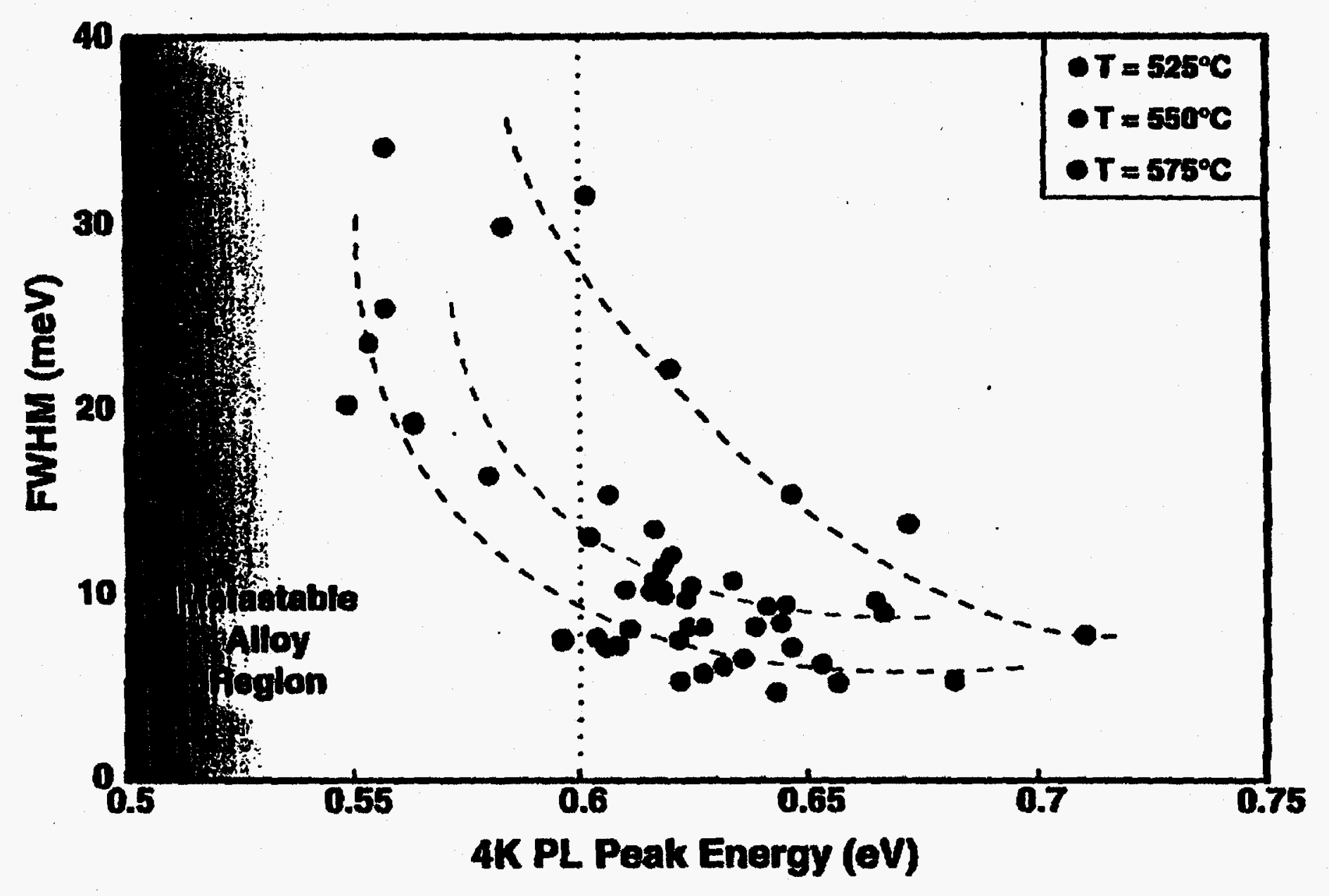

V Lewgraph 10 


\section{IEIM Contrast Modulation in $\mathbf{G a}_{1-\mathrm{x}} \mathbf{I n}_{\mathbf{x}} \mathrm{As}_{\mathbf{y}} \mathrm{Sb}_{1-\mathrm{y}}$}

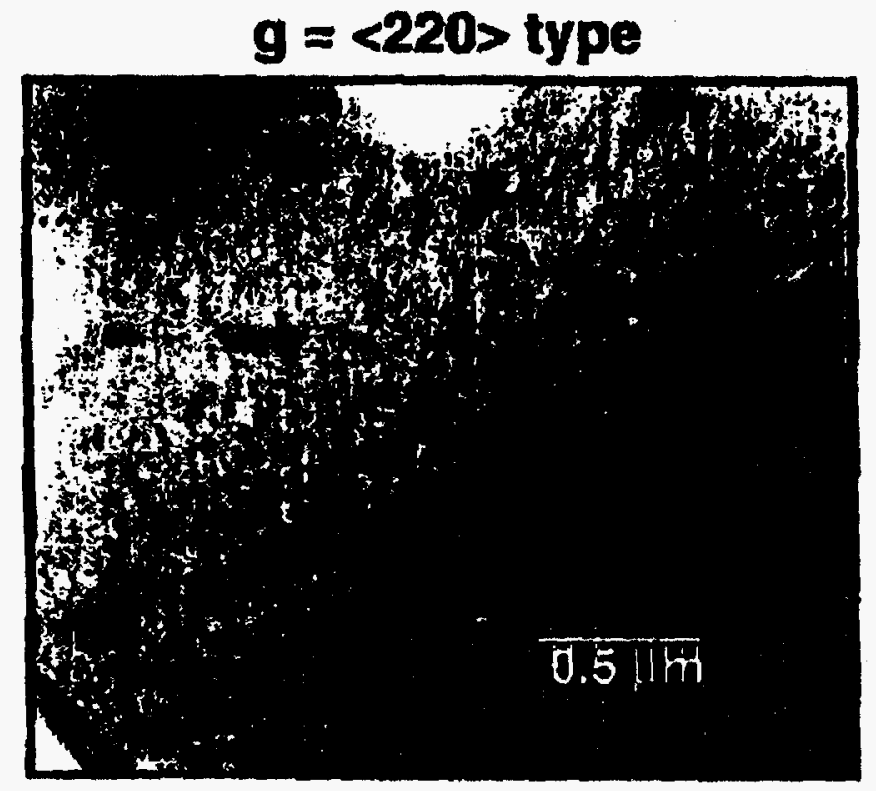

$x=0.06, y=0.05$

RT PL $=1.92 \mu \mathrm{m}$

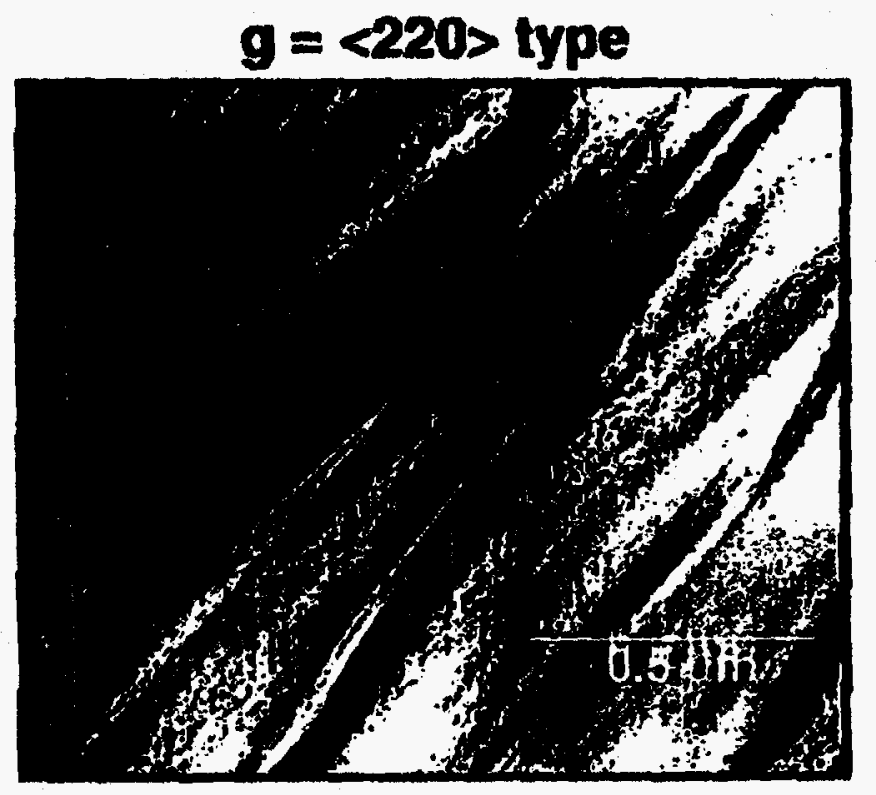

$x=0.18, y=0.14$ RT PL $=2.4 \mu \mathrm{m}$ 


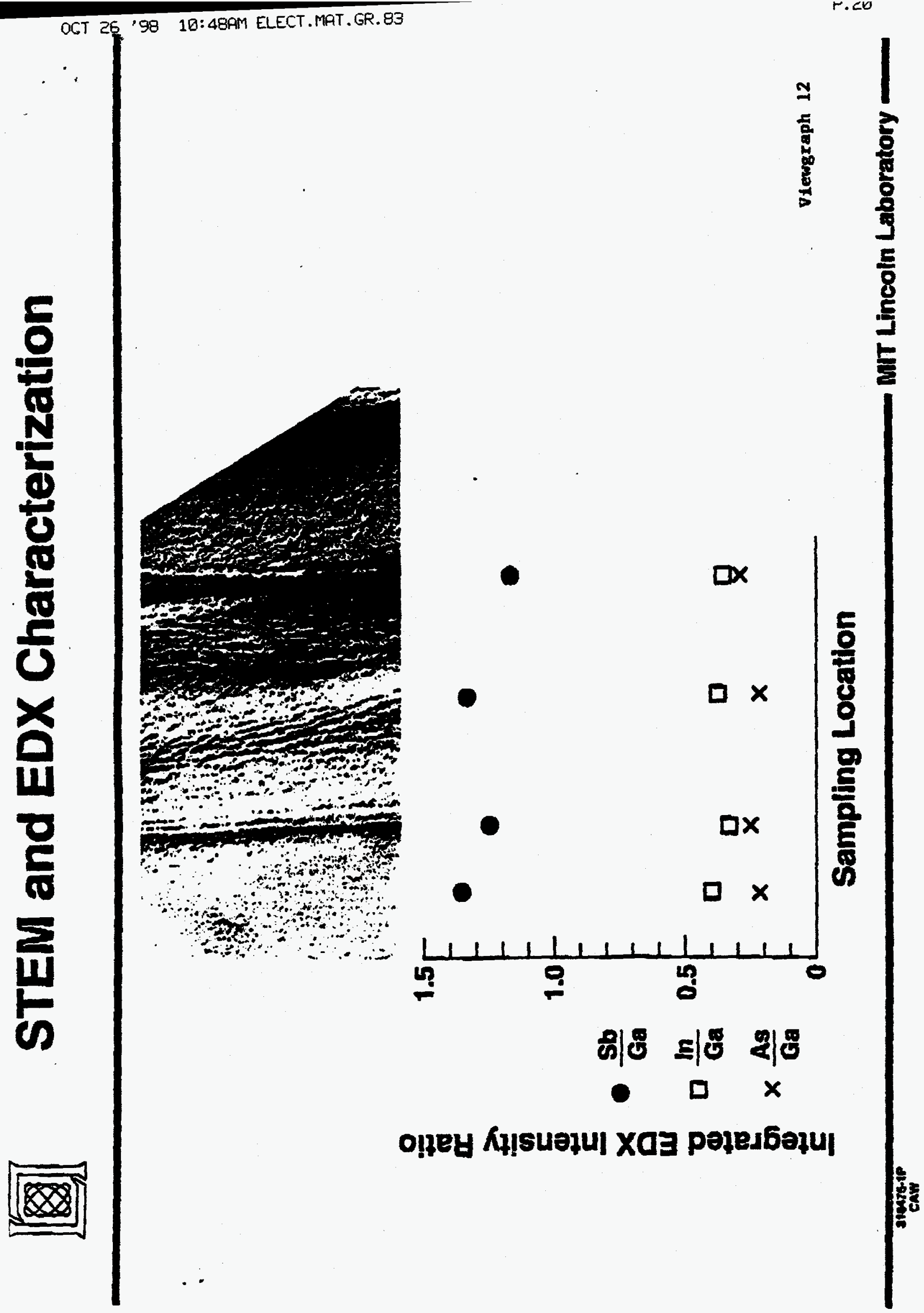




\section{Electrical Characteristics of p-GalnAsSb}

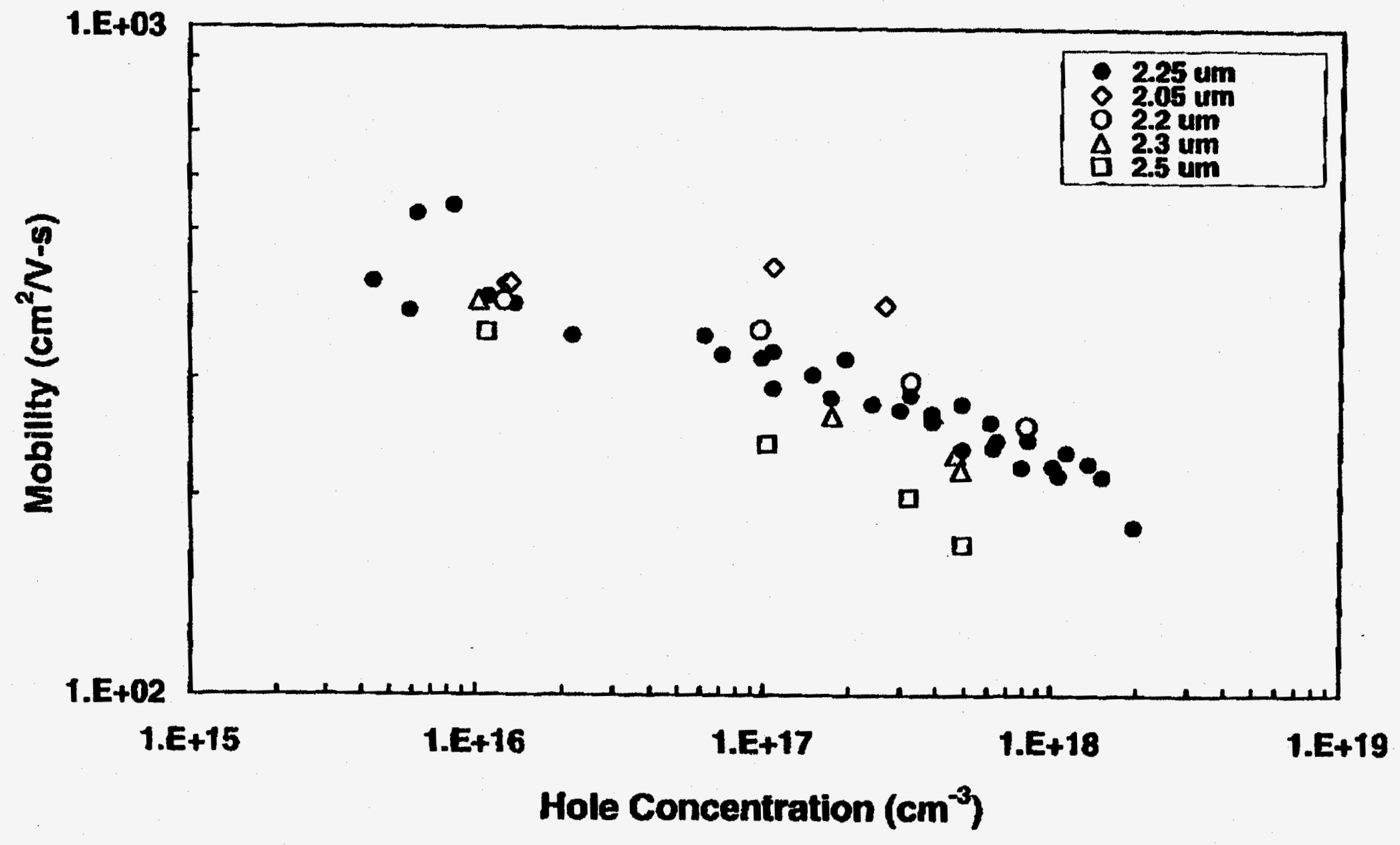

V1eugraph 13 
dopines25-3.98.x16,n-In-vg.92498

\section{Electrical Characteristics of $\boldsymbol{n}$-GalnAsSb}

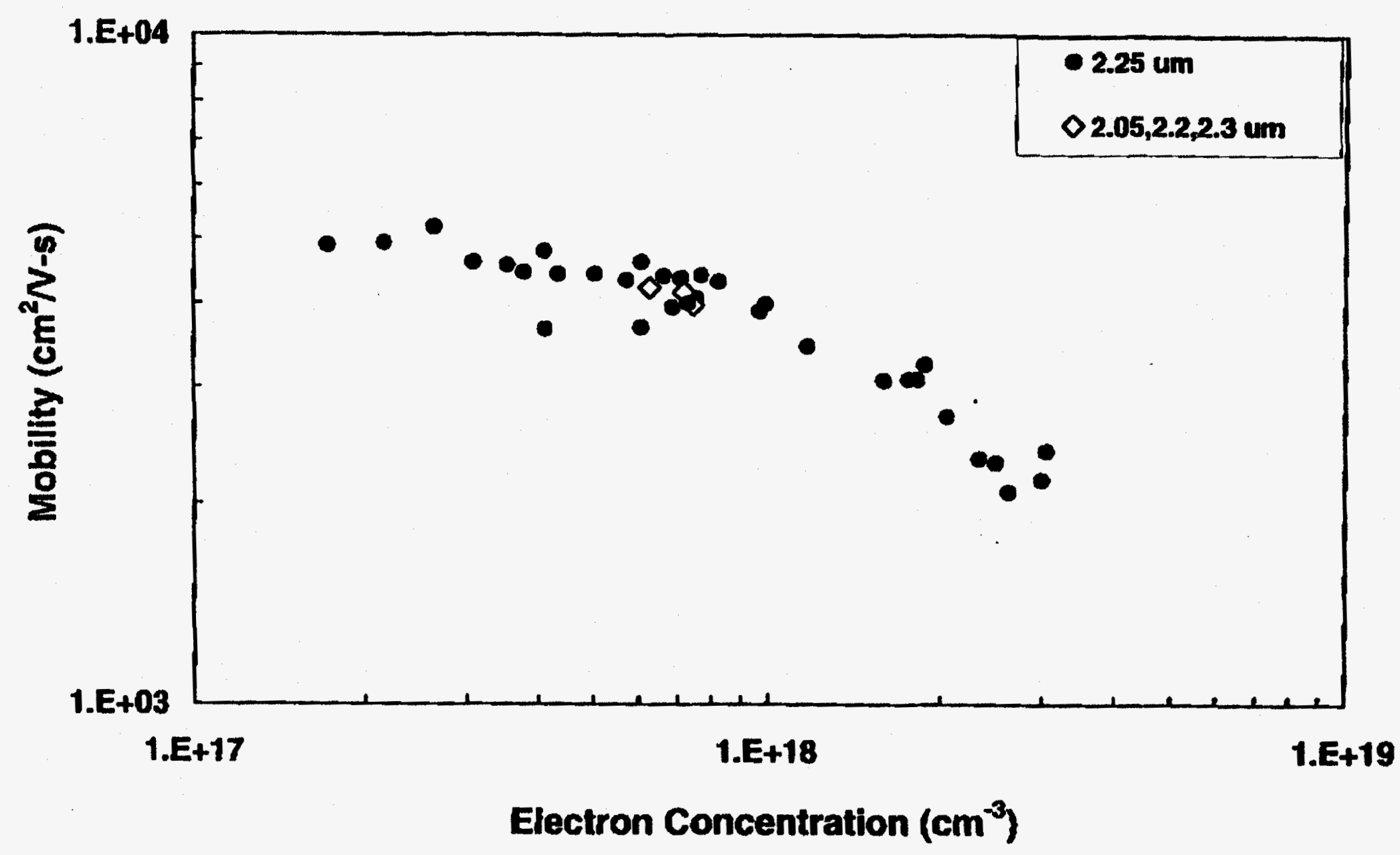




\section{GalnAsSb/GaSb TPV Structure}

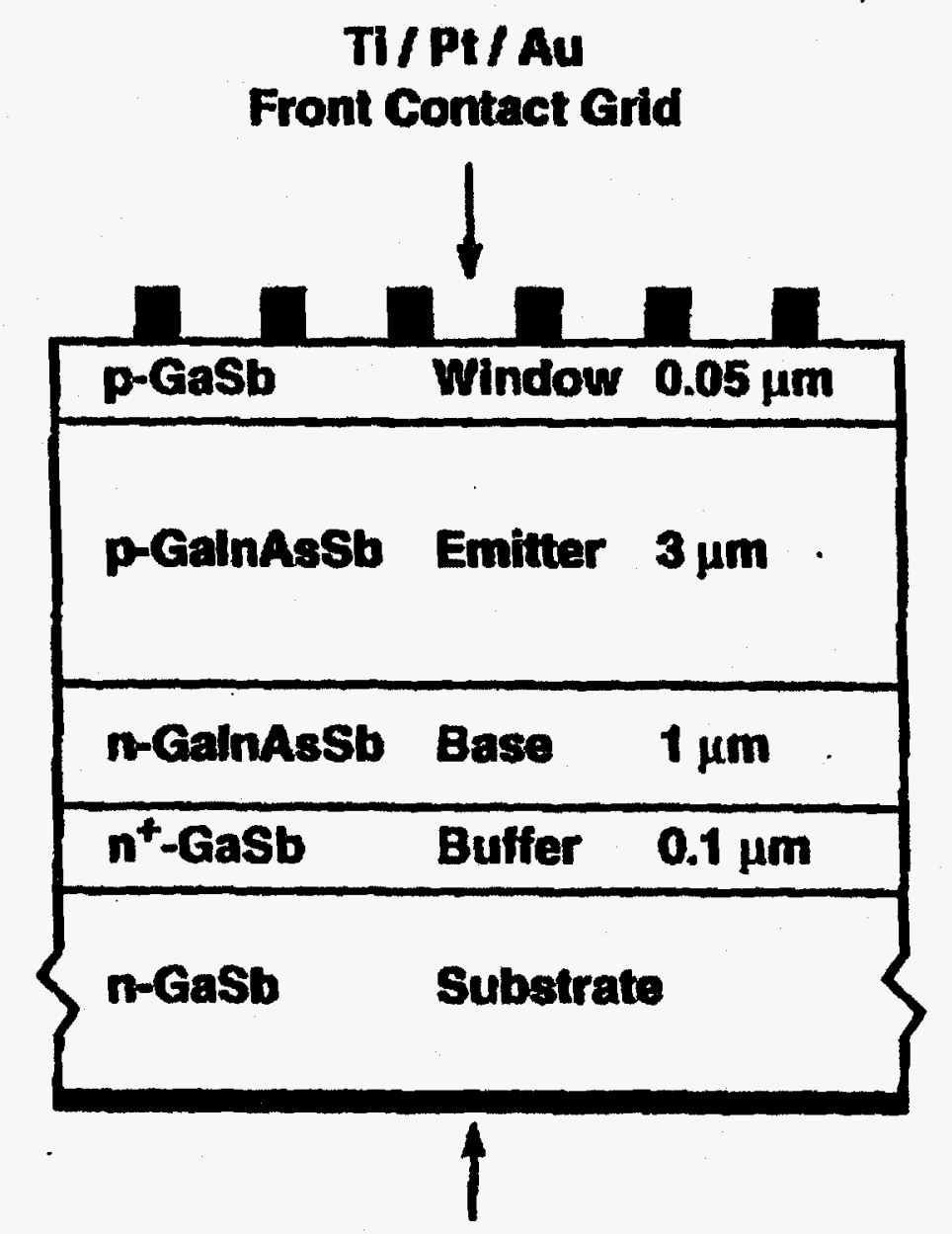

Au / Sn / Ti / Pt / Au

Viewgraph 15 Back Contact 


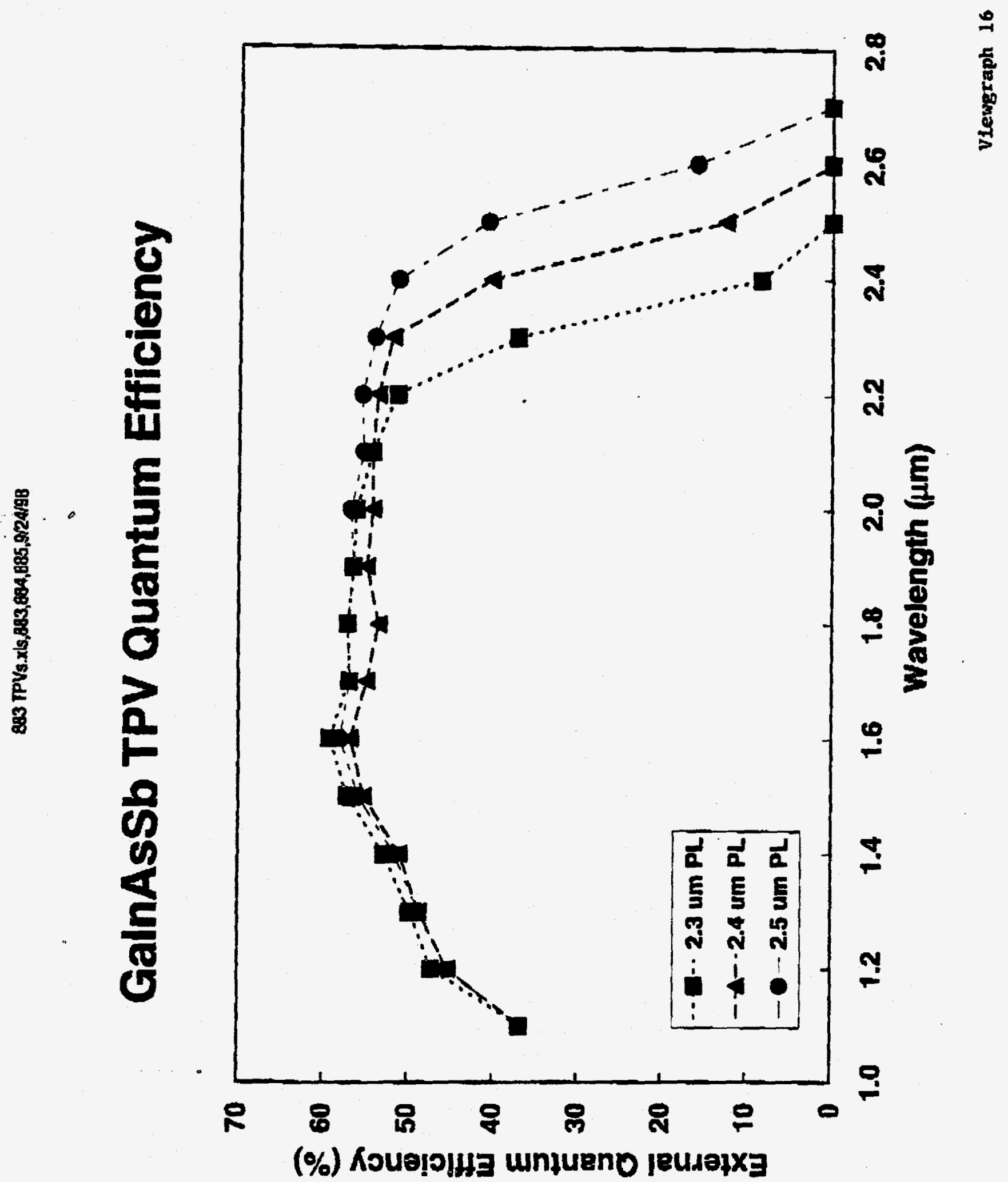

